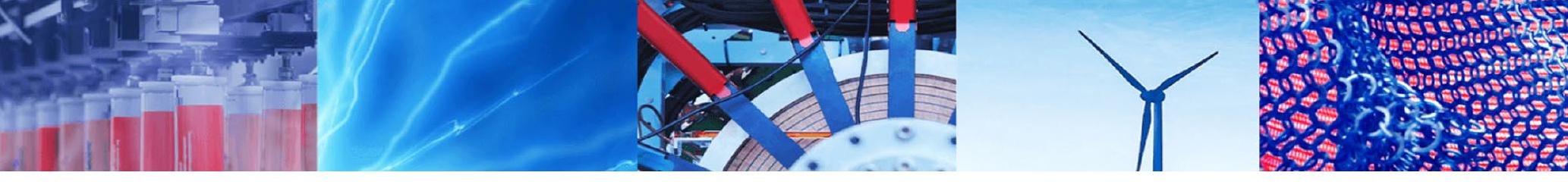

Research Article

\title{
Impedimetric detection of Banana bunchy top virus using CdSe quantum dots for signal amplification
}

\author{
S. Majumder ${ }^{1}$ (D) Bhaskar Bhattacharya ${ }^{2} \cdot$ Pramod K. Singh $^{3} \cdot$ Shivangi Johari $^{1} \cdot$ Bharat Singh $^{1} \cdot$ Razia Rahman $^{1}$
}

Received: 18 October 2019 / Accepted: 26 February 2020 / Published online: 13 March 2020

(c) Springer Nature Switzerland AG 2020

\begin{abstract}
Banana bunchy top virus is considered to be the most economically destructive pathogens of banana that causes severe economic loss in banana plantations worldwide, including India. In this present study we have developed an improved electrochemical ELISA for detection of Banana bunchy top virus (BBTV). For enhanced and accurate detection we have used cadmium selenide (CdSe) quantum dots (QDs) as signal amplifiers. Experiments in this study were performed using primary antibody raised from recombinant coat protein of BBTV. CdSe QDs could significantly amplify the electrical signals in this assay and make the method appropriate for lab use. The result of electrical conduction showed the difference of impedance between the healthy and diseased sample of the order of $\sim 100 \Omega$. The electrochemical ELISA could detect the virus in plant sap up to dilution of 1:25 as compared to 1:10 of conventional ELISA.
\end{abstract}

Keywords Banana bunchy top virus · Faradic impedance spectroscopy · Cadmium selenide quantum dots (CdSe QDs)

\section{Introduction}

Banana is the major staple food crop for approximately 400 million people [1]. In terms of value of production, banana is fourth most important food crop of developing world and a source of livelihood for millions [2]. According to FAOSTAT data of 2016, the volume of global gross banana exports was 20 million tones. This figure indicates the enormity of the trading involved in banana and thus its contribution towards economy of the countries involved in its cultivation. Viral diseases are considered to be the most economically destructive pathogens of banana. Banana bunchy top virus (BBTV), Cucumber mosaic virus (CMV), Banana bract mosaic virus (BBrMV), Banana streak virus (BSV), are the four major viruses known to cause severe economic loss in banana plantations worldwide, including India [3-6]. Food security of 15 Sub Saharan African countries is being threatened by the arrival and spread of Banana bunchy top disease along with banana Xanthomonas wilt (http://www.fao. org/agriculture/crops/news-events-bulletins/detail/en/ item/36259/icode/3/?no_cache=1). In absence of resistant varieties, eradication, exclusion and use of certified virus free mother plants are the most essential component for disease management strategy $[4,7]$. Therefore, an efficient indexing method or device is necessary for early diagnosis and management. It will also play a vital role in preventing the spread of disease and eliminating the waste of resources on futile therapeutic strategies $[8,9]$.

The various diagnostic methods used for screening banana germplasm include symptoms, cytology, histology, serological assays and nucleic acid based assays [10, 11]. ELISA is the most used indexing method for preliminary detection because of its low-cost, simplicity, easy

Bharat Singh and Razia Rahman have contributed equally to this work.

S. Majumder, shahanamajumder@gmail.com | Department of Biotechnology, School of Engineering and Technology, Sharda University, Greater Noida 201306, India. ' Department of Physics, Mahila Maha Vidhyalaya, Banaras Hindu University, Varanasi 221005, India. ${ }^{3}$ Department of Physics, School of Basic Sciences and Research, Sharda University, Greater Noida 201310, India. 
reading and its ability to handle many samples at one time $[12,13]$. The general principle behind a conventional ELISA is the antibody mediated capture and the detectionof an antigen through a measurable product [14]. Detection of the antigen-antibody reaction requires antibody to be conjugated with an enzyme that can give a quantifiable reaction, usually an insoluble chromogenic end product. However, various components of this method can limit its efficiency. Being an optical method the measurement requires highly efficient light source detector which may pick false signals from the complex colored samples [15]. Owing to limitations of Lambert-Beer law applied by the spectrophotometer, at least a minimum sample volume is required to achieve a level of sensitivity. Another component, on which performance of ELISA is dependent, is the substrate [16]. Owing to these limitations, for last two decades, electronic immunosensors are attracting much interest for their direct monitoring methods which are more sensitive, rapid and cost effective than conventional immunoassay techniques. Immune-sensors with electrochemical transducers though use antigen-antibody interaction as in ELISA apply non-enzymatic detection by measuring changes in the resistance at electrode surface [17]. They are proving to be better alternatives [18-21].

Limited availability of samples and uncertain cases of low antigen concentration dictate the need of enhanced signal during diagnostic procedures. As the concentration of virus particle varies throughout the infection period the method developed should be able to detect the negligible amount of infectious virus particle in host system. For last two decades simple direct monitoring methods are gaining importance because they are sensitive, rapid and cost effective than conventional immunoassay techniques $[20,22,23]$. Preparing electrode surfaces in a manner that it converts biological events into electronic signals has been the basis of development of biosensors, immunosensors, and bioelectronic devices [24-26]. The binding of a specific antigen to antibody recognition layer could generate electronic signals that could be detected by various methods [27]. Measurements by impedimetric method are most advantageous as enzyme labeling is not required.

In this study we have used the faradic impedance spectroscopy as electrochemical sensing method to detect a successful antigen-antibody attachment. Nanoparticles like quantum dots (QDs) show electrical conductance properties [28-31]. We have used CdSe QDs to amplify the signal of this electrochemical reaction (antigen-antibody interaction) to a level, where it can be used as a routine indexing assay. Interaction of BBTV and antibodies raised against it have been used to standardize this assay.

SN Applied Sciences

\section{Materials and methods}

\subsection{Source of plant material}

Banana samples showing prominent bunchy top symptoms were collected from four states of India viz., Nadia (West Bengal), Punalur (Kerala), Raipur (Chhattisgarh) and Nazira (Assam) during a survey conducted in 2016. BBTV infection in the samples was confirmed by PCR as described earlier [32]. The positive samples were maintained in the departmental glass house. Disease free tissue cultured healthy plants were procured from Devleela Biotech, Raipur and used as negative/healthy control.

\subsection{Antibody}

Experiments in this study were performed using antibody raised from recombinant coat protein of BBTV. Antibody against recombinant coat protein of BBTV was produced and evaluated by methods described earlier [33].

\subsection{Direct antigen coated ELISA}

PCR positive BBTV infected banana leaves (from four different states of India) and healthy leaves were subjected to DAC ELISA using methods as described earlier [33].

\subsection{Synthesis and purification of quantum dots}

Cadmium selenide (CdSe) quantum dots (QD) were synthesised by low temperature method described elsewhere [34]. Optical measurements were carried out in a Shimadzu-1501 spectrophotometer by preparing a suspension solution of CdSe QD in double distilled water in the proportion of 1:20 which was put in the cuvette for optical absorption measurements in the already calibrated spectrophotometer.

\subsection{Conjugation of quantum dots}

Blue colored (1.7-1.9 nm) QD particles were used for conjugation to streptavidin at Merck, Bangalore (Fig. 1a, b).

\subsection{Electrical measurements with QD}

All electrochemical measurements were carried out in the frequency range $1 \mathrm{MHz}$ to $100 \mathrm{~Hz}$ using $\mathrm{CHI}$ Electro-chemical Workstation (model 604D, USA). To measure conductivity $(\sigma)$, samples were tested using special design electrodes. The conductivity or bulk resistance was calculated using the following formula $\sigma=\mathrm{G} \cdot \mathrm{I} / \mathrm{A}$ 

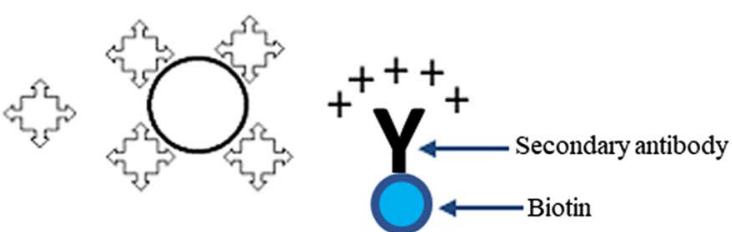

a

b
C

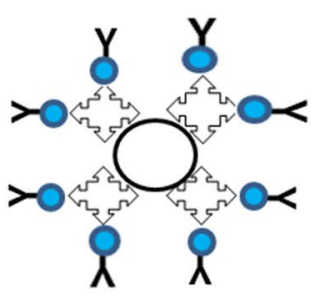

d

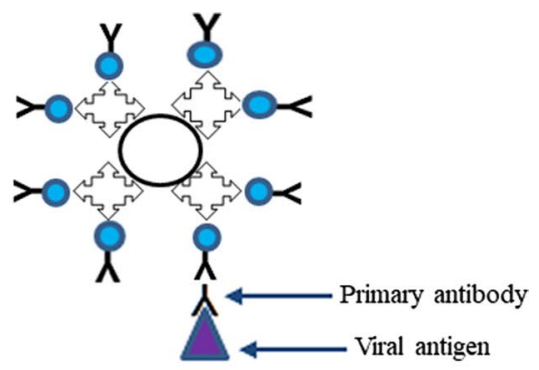

e
Fig. 1 Schematic illustration of the development of streptavidin functionalized quantum dots and its application in direct antigen coated-type immunoassay a streptavidin, b functionalized quantum dots, c biotinylated secondary antibody, d functionalized

where $G=1 / R_{\mathrm{b}}$ where $G$ was conductance and $R_{\mathrm{b}}$ was bulk resistance. The bulk resistance obtained from the intercept of the real part of complex impedance plot, and $I$ and $A$ are the thickness and area of sample respectively. Figure 1, shows the scheme of the assay. BBTV infected banana leaves from all the four states and healthy leaves from BBTV free tissue culture plants $(0.1 \mathrm{~g})$ were ground in $2.0 \mathrm{ml}$ sodium carbonate buffer ( $\mathrm{pH} 9.6)$ containing $2 \%$ polyvinylpyrrolidone (PVP, MW 40,000). The extracts were centrifuged at 10,000 rpm for $2 \mathrm{~min}$ and supernatant was transferred to a fresh tube. Six wells of a 96-well plate were coated with $200 \mu$ l of extract from healthy leaf and used as healthy control wells. Six wells were coated with $200 \mu$ supernatant of extract from infected leaf. Six wells were coated with $200 \mu \mathrm{l}$ of buffer and treated as buffer control. The plate was incubated overnight at $4{ }^{\circ} \mathrm{C}$. Subsequent to the absorption, the plates were washed three times with phosphate-buffered saline containing $0.01 \%$ Tween 20 (PBST). The plate was then blocked with blocking solution containing $1 \%$ BSA dissolved in PBS-T. After Incubating for $1 \mathrm{~h}$ at $37^{\circ} \mathrm{C}$, the plates were washed three times with PBS-T. $200 \mu$ l primary anti-BBTV antibody (raised in-house) diluted in PBS TPO (1:700) was added to each reaction wells and incubated at $37^{\circ} \mathrm{C}$ for $1.5 \mathrm{~h}$. Another set of washing was done to remove any unattached antibody. A solution was prepared using Streptavidin conjugated QD and biotinylated anti-rabbit secondary antibody (Sigma-Aldrich, USA) in PBS-TPO at $1: 200$ ratio and incubated for $30 \mathrm{~min}$ at $25^{\circ} \mathrm{C} .200 \mu \mathrm{l}$ of this solution containing biotinylated anti-rabbit secondary antibody attached to Streptavidin conjugated QD, were added to each reaction well. Plate was incubated at $25^{\circ} \mathrm{C}$ for $30 \mathrm{~min}$. After another set of washing and addition of $200 \mu \mathrm{I}$ PBS TPO to each well, reading was taken using a two platinum electrode configuration. Electrodes were fixed on a Perspex slab in order to keep the distance between them constant at $\sim 7 \mathrm{~mm}$, so as to quantum dots attached to biotinylated secondary antibody, e the secondary antibody recognizes primary antibody which in turn is attached to the viral antigen

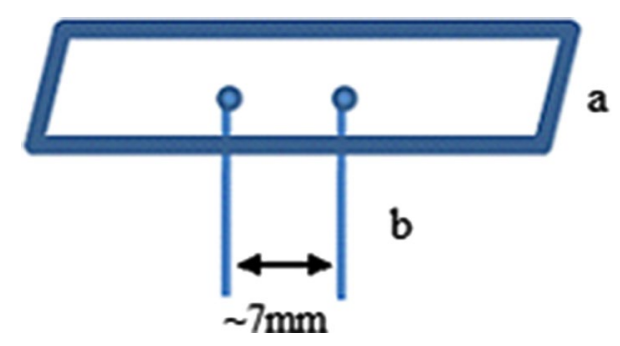

Fig. 2 Schematic illustration of the instrument used for measurement of impedance $\mathbf{a}$ perspex slab, $\mathbf{b}$ platinum electrodes

fit in the well effortlessly (Fig. 2). Maximum peak to peak signal was $5 \mathrm{mV}$ so as to avoid any other potential driven reaction. Electrode was cleaned vigorously with ethanol after each reading.

\subsection{Comparison between ELISA and electrochemical ELISA}

To compare the efficacy of both electrochemical ELISA and conventional ELISA, different sap dilutions of a PCR positive sample were tested. One tissue culture raised healthy sample was used as negative control. Procedures were repeated as in previous sections. Most of the reagents used in all the assays were the same to avoid variation caused by reagent selection. The anti BBTV antibody (raised in-house) was used at 1:700. Plant sap was used at 1 to $10^{-4}$ dilution. BSA $1 \%$ was used for blocking in all the formats. The cut-off value for scoring positive reaction in ELISA was twice the average of healthy readings. The cut-off value for scoring positive reaction in Electrochemical ELISA was fixed at a difference in impedance of the order of $80 \Omega$ between healthy and diseased sample. The negative samples were reconfirmed by performing PCR for BBTV. Five replicates of each dilution was evaluated. 
Table 1 Results of indexing banana samples for BBTV using ELISA

\begin{tabular}{lll}
\hline Sample no. & Analyte & $\begin{array}{l}\text { ELISA OD } \\
\text { at } 450 \mathrm{~nm}^{\mathrm{a}}\end{array}$ \\
\hline 1 & Buffer & 0.080 \\
2 & Healthy & 0.272 \\
3 & Diseased samples & \\
4 & West Bengal & 0.820 \\
5 & Kerala & 0.671 \\
6 & Assam & 0.862 \\
\hline
\end{tabular}

avalues are average of five readings

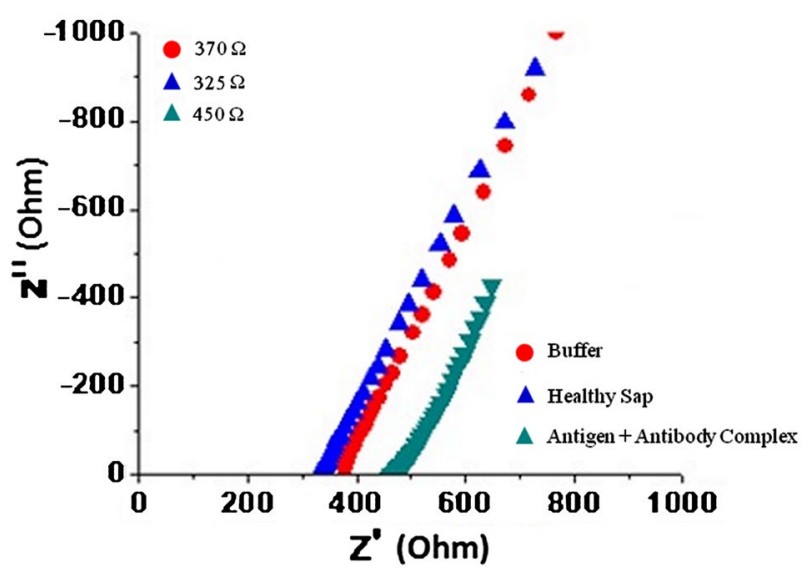

Fig. 3 Complex impedance plot (cole-cole plot) of buffer only, healthy sap and viral antigen and antibody complex with Streptavidin conjugated QDs in buffer

\section{Results}

\subsection{Elisa}

DAC ELISA with antibody raised in-house, generated strong signal for diseased samples. The cut-off value for scoring positive reaction was kept at twice the average healthy readings (OD 0.272) at 1:700 dilution of antibody (Table 1). As can be observed the values vary from sample to sample. But all the positive samples showed OD at least two times higher than healthy samples.

\subsection{Electrochemical ELISA with streptavidin conjugated QD}

A series of complex impedance data samples were evaluated. One typical data (cole-cole plot) is shown in Fig. 3. It is clear from the figure and table that solution PBST-PO buffer shows good conduction with impedance value $|Z|=370 \mathrm{ohm}$. The impedance is less in wells where healthy extract is used which signifies the absence of unwanted molecules. In contrast to the previous reactions, electrical impedance shows a significant increase when biotinylated secondary antibody and Streptavidin conjugated with QDs are used in the wells containing BBTV infected leaf sap (Table 2). The increase in impedance of the antigen + antibody complex is attributed to the presence of diseased bodies. The difference of impedance between the wells containing healthy leaf sap and antibody complex and wells containing infected leaf sap (antigen) and antibody complex is of the order of $\sim 100 \Omega$ (Table 2). This difference is variable for different samples (Table 2) but clearly impedance decreases in wells when viral antigen is present in the sap.

\subsection{Comparison between ELISA and electrochemical ELISA}

QD based electrochemical ELISA could detect the virus up to sap dilution of 1:25. Whereas conventional ELISA could detect up to 1:10 (Table 3). The QD based method was found to be more sensitive than conventional ELISA. Tissue culture raised healthy sample and buffer control tested negative which further verifies its accuracy.
Table 2 A comparison of impedance change at various stages of electrochemical ELISA using functionalized CdSe Quantum Dots

\begin{tabular}{lll}
\hline Sample no. & Composition & $\begin{array}{l}\text { Electrical resist- } \\
\text { ance }(\Omega) \text { with } \\
\text { QDs }^{\mathrm{a}}\end{array}$ \\
\hline 1 & Buffer solution & 370 \\
2 & Healthy sap + antibody complex & 330 \\
3 & Diseased sap (West Bengal isolate) + antibody complex & 445 \\
4 & Diseased sap (Kerala isolate) + antibody complex & 436 \\
5 & Diseased sap (Assam isolate) + antibody complex & 450 \\
6 & Diseased sap (Chhattisgarh isolate) +antibody complex & 455 \\
\hline
\end{tabular}

${ }^{a}$ Values are average of five readings 
Table 3 A comparison of ELISA and electrochemical ELISA

\begin{tabular}{llll}
\hline Sample no. & Analyte & $\begin{array}{l}\text { ELISA (OD at } \\
405 \mathrm{~nm})\end{array}$ & $\begin{array}{l}\text { Electrochemical ELISA with } \\
\text { streptavidin conjugated } \\
\text { QDs }\end{array}$ \\
\hline 1 & & - & - \\
2 & Buffer & - & - \\
3 & Healthy & + & + \\
4 & Diseased plant extract with no dilution & + \\
5 & Diseased plant extract with 1:5 dilution & + \\
6 & Diseased plant extract with 1:10 dilution & + & + \\
7 & Diseased plant extract with 1:25 dilution & - & - \\
8 & Diseased plant extract with 1:50 dilution & - & - \\
\hline
\end{tabular}

\section{Discussion}

In this present study we have developed an electrochemical ELISA where electronic signals were used for detection. Signal enhancement by bio-functional nanomaterials like Gold nanoparticles and quantum dots are used frequently due to their semiconductor and biocompatible properties [35-37]. Gold nanoparticles (AuNPs) and QDs can provide a natural environment for bimolecular immobilization and facilitate the electron-transfer because of their high surface area and electrochemistry [38-40]. They are also preferred over the enzymes as nanoparticles are stable against photobleaching and are not prone to environmental degradation due to their inorganic composition $[41,42]$.

When Streptavidin conjugated QDs were used, a sharp increase in impedance was observed in the diseased samples. In this study we have conjugated QDs to streptavidin as it has a better affinity for biotin than avidin. QDs are known to couple to streptavidin directly through an active ester coupling reaction [43]. This usually results in 5-10 streptavidin covalently attached on the surface of QDs. Streptavidin which is a tetravalent protein, can bind to four biotin on it four active sites and affinity between streptavidin and biotin is one of the strongest non-covalent interactions in nature [44]. So if one site is used for attaching to QD three more is free to attach to biotin. In this study we have separately incubated the streptavidin conjugated QDs with biotinylated secondary antibody so as to give these two molecules time to interact properly. Once they react, it is expected that more than one secondary antibody gets attached to the streptavidin at multiple attachment sites (Fig. 2d). Hence each streptavidin attached to a QD, can be attached to more than one biotinylated antibody [45]. Though all of these biotinylated antibody can bind to multiple analyte but reports indicate that only one binds and the rest are free (Fig. 2e). Hence this complex in our experiment will bind to one primary antibody and the rest attached to other streptavidin molecule on same QD will act as charge carriers. These unbound charges lead to neutralization of free moving charge carriers in the buffer solution resulting in enhanced overall impedance value (Table 2). Thus there is a change in impedance by more than $\sim 40 \%$ of its initial value. In buffer control, the electrical conduction is primarily due to dissolved salts in ionic state. The conductivity did not change on addition of antibodies to the wells containing healthy samples and buffer, as the antibodies could not attach to the wells in absence of appropriate antigen. As these wells lacked the additional neutralizing charges found on antibodies no significant change in impedance were observed.

The conventional ELISA performed in this study successfully detected presence of BBTV. The OD indicated towards the titer of viral antigen present in the solution. A similar variation was also observed in electrochemical ELISA. This variation could be directly proportional to the quantity of antigens present, and which in turn will be directly linked to the number of antibody conjugates used for signal amplification.

Biosensors usually consist of three components viz., one that recognizes the analyte and produces a signal, a signal transducer and a reader. Immunosensors use antibody antigen interaction to generate signals. Among the various transduction techniques, impedance spectroscopy is an effective method to detect the signal of this interaction. The probing principle we have used in our assay is the change in the electron-transfer features in the buffer owing to antibody-antigen interaction. Biosensor techniques often require surface regeneration after each measurement which makes the process complicated for frequent use in a diagnostic set up. It also makes it costlier. Therefore, we have eliminated the surface regeneration step and used a DAC ELISA format for probing.

In this investigation we could produce robust signals by using nanomaterials with semiconductor properties and make the methods appropriate for lab use. In the electrochemical method use of enzyme-substrate is eliminated. Instead antibodies were conjugated with non-enzymatic 
reporter molecules. This methodology saves the expense of the enzyme conjugates and their substrate. This change not only reduces the cost but also the time required for additional steps. Thus, makes the processes cheaper and rapid.

In this study low sensitivity of traditional ELISA has been raised to the level of electrochemical methods without compromising its user friendliness and cost effectiveness. Both the systems are equally viable to be used in indexing labs depending on the facility and ease of development.

Acknowledgements The authors would like to thank Department of Biotechnology, Government of India, for the financial assistance in conducting this study [BT/PR12232/BPA/118/54/2015].

\section{Compliance with ethical standards}

Conflict of interest The authors declare that they have no conflict of interest in the publication.

\section{References}

1. Jain SM, Swennen R (2004) Banana improvement: cellular, molecular biology, and induced mutations. Science Publishers, Enfield

2. Frison EE, Escalant JV, Sharrock S (2001) The global Musa genomic consortium: a boost for banana improvement. In: Jain SM, Swennen R (eds) Banana improvement: cellular, molecular biology and induced mutations. Science Publishers, Enfield, pp 24-28

3. Selvarajan $R$, Balasubramanian V (2008) Banana viruses. In: Rao GP, Myrta A, Ling KS (eds) Characterization, diagnosis and management of plant viruses. Studium Press LLC, Houston, pp 109-124

4. Geering ADW (2009) Viral pathogens of banana: outstanding questions and options for control. Acta Hortic 828:39-50. https ://doi.org/10.17660/ActaHortic.2009.828.2

5. Lockhart BE (2011) Viruses that threaten banana and plantain production in the Caribbean. In: Proceedings of the 47th annual meeting of Caribbean food crops society. Barbados

6. Kumar PL, Selvarajan R, Iskra-Caruana ML, Chabannes M, Hanna $R$ (2015) Biology, etiology, and control of virus diseases of banana and plantain. In: Loebenstein G, Katis NI (eds) Advances in virus research, vol 91. Academic Press, London, pp 229-269

7. Dale JL (1987) Banana bunchy top: an economically important tropical plant virus disease. Adv Virus Res 33:301-325

8. Daar AS, Thorsteinsdóttir H, Martin DK, Smith AC, Nast S, Singer PA (2002) Top ten biotechnologies for improving health in developing countries. Nat Genet 32:229-232

9. Rusling JF, Kumar CV, Gutkind JS, Patel V (2010) Measurement of biomarker proteins for point-of-care early detection and monitoring of cancer. Analyst 135:2496-2511

10. Storch GA (2000) Diagnostic virology. Clin Infect Dise 31:739-751

11. Lockhart BE (2013) Certification of virus infection status of banana and plantain germplasm and propagating stock: some questions and a few answers. In: Proceedings of XX Acorbat international meeting. Brazil

12. Lequin RM (2005) Enzyme immunoassay (EIA)/enzyme-linked immunosorbent assay (ELISA). Clin Chem 51:2415-2418
13. Luo Y, Zhang B, Chen M, Jiang T, Zhou D, Huang J, Fu W (2012) Sensitive and rapid quantification of $C$-reactive protein using quantum dot-labeled microplate immunoassay. J Trans Med. https://doi.org/10.1186/1479-5876-10-24

14. Hnasko R, Lin A, McGarvey JA, Stanker LH (2011) A rapid method to improve protein detection by indirect ELISA. Biochem Biophys Res Commun 410:726-731. https://doi.org/10.1016/j. bbrc.2011.06.005

15. Ricci F, Adornetto G, Palleschi G (2012) A review of experimental aspects of electrochemical immunosensors. Electrochim Acta 84:74-83. https://doi.org/10.1016/j.electacta.2012.06.033

16. Aziz N, Nishanian P, Mitsuyasu R, Detels R, Fahey JL (1999) Variables that affect assays for plasma cytokines and soluble activation markers. Clin Diagn Lab Immunol 6:89-95

17. Zhu Z, Shi L, Feng H, Zhou HS (2015) Single domain antibody coated gold nanoparticles as enhancer for Clostridium difficile toxin detection by electrochemical impedance immunosensors. Bioelectrochem 101:153-158

18. Patolsky F, Filanovsky B, Katz E, Willner I (1998) Photoswitchable antigen-antibody interactions studied by impedance spectroscopy. J Phys Chem 102:10359-10367. https://doi.org/10.1021/ jp983700n

19. Wang J, Ibáñez A, Chatrathi MP, Escarpa A (2001) Electrochemical enzyme immunoassays on microchip platforms. Anal Chem 73:5323-5327

20. Wang J (2006) Analytical electrochemistry. Wiley, New York

21. Loaiza ÓA, Jubete E, Ochoteco E, Cabañero G, Grande H, Rodríguez J (2011) Gold coated ferric oxide nanoparticles based disposable magnetic genosensors for the detection of DNA hybridization processes. Biosens Bioelectron 26:2194-2200. https://doi.org/10.1016/j.bios.2010.09.034

22. Scheller FW, Schubert F, Fedrowitz J (2013) Frontiers in biosensorics I: fundamental aspects. Birkhäuser Verlag, Basel

23. Skládal $P$, Kovář $D$, Krajíček V, Šišková $P$, Přibyl J, Švábenská E (2013) Electrochemical immunosensors for detection of microorganisms. Int J Electrochem Sci 8:1635-1649

24. Willner B, Blonder R, Heleg-Shabtai V, Bückmann AF (1997) Assembly of functionalized monolayers of redox proteins on electrode surfaces: novel bioelectronic and optobioelectronic systems. Biosens Bioelectron 12:337-356

25. Ghindilis AL, Atanasov P, Wilkins M, Wilkins E (1998) Immunosensors: electrochemical sensing and other engineering approaches. Biosens Bioelectron 13:113-131. https://doi. org/10.1016/S0956-5663(97)00031-6

26. Chikkaveeraiah BV, Bhirde AA, Morgan NY, Eden HS, Chen X (2012) Electrochemical immunosensors for detection of cancer protein biomarkers. ACS Nano 6:6546-6561. https://doi. org/10.1021/nn3023969

27. Pei R, Cheng Z, Wang E, Yang X (2001) Amplification of antigen-antibody interactions based on biotin labeled proteinstreptavidin network complex using impedance spectroscopy. Biosens Bioelectron 16:355-361. https://doi.org/10.1016/S0956 -5663(01)00150-6

28. Daniel MC, Astruc D (2004) Gold nanoparticles: assembly, supramolecular chemistry, quantum-size-related properties, and applications toward biology, catalysis, and nanotechnology. Chem Rev 104:293-346. https://doi.org/10.1021/cr030698+

29. Cui R, Pan HC, Zhu JJ, Chen HY (2007) Versatile immunosensor using CdTe quantum dots as electrochemical and fluorescent labels. Anal Chem 79:8494-8501. https://doi.org/10.1021/ac070 923d

30. Li Y, Schluesener HJ, Xu S (2010) Gold nanoparticle-based biosensors. Gold Bull 43:29-41

31. Cao X, Ye Y, Liu S (2011) Gold nanoparticle-based signal amplification for biosensing. Anal Biochem 41:1-16. https://doi. org/10.1016/j.ab.2011.05.027 
32. Majumder S, Bhattacharya B, Singh PK, Johari S (2013) Detection of banana bunchy top virus using impedance spectroscopy. Sens Lett 11:2055-2059. https://doi.org/10.1166/sl.2013.3061

33. Majumder S, Johari S (2018) Development of a gold-nano particle based novel dot immunobinding assay for rapid and sensitive detection of Banana bunchy top virus. J Virol Methods 255:23-28. https://doi.org/10.1016/j.jviromet.2018.01.015

34. Surana K, Salisu IT, Mehra RM, Bhattacharya B (2018) A simple synthesis route of low temperature $\mathrm{CdSe}-\mathrm{CdS}$ core-shell quantum dots and its application in solar cell. Opt Mater 82:135-140

35. Kumar A, Boruah BM, Liang XJ (2011) Gold nanoparticles: promising nanomaterials for the diagnosis of cancer and HIV/AIDS. J Nanomater 22:1-18

36. Morales-Narváeza E, Pérez-Lópeza B, Pires LB, Merkoçi A (2012) Simple Förster resonance energy transfer evidence for the ultrahigh quantum dot quenching efficiency by graphene oxide compared to other carbon structures. Carbon 50:2987-2993

37. Jacobs M, Selvam AP, Craven JE, Prasad S (2014) Antibodyconjugated gold nanoparticle-based immunosensor for ultrasensitive detection of troponin-T. J Lab Autom 19:546-554. https ://doi.org/10.1177/2211068214538971

38. Ambrosi A, Castañeda MT, Killard AJ, Smyth MR, Alegret S, Merkoçi A (2007) Double-codified gold nanolabels for enhanced immunoanalysis. Anal Chem 79:5232-5240. https:// doi.org/10.1021/ac070357m

39. Ambrosi A, Airo F, Merkoçi A (2009) Enhanced gold nanoparticle based ELISA for a breast cancer biomarker. Anal Chem 82:11511156. https://doi.org/10.1021/ac902492c
40. de la Escosura-Muñiz A, Sánchez-Espinel C, Díaz-Freitas $B$, González-Fernández Á, Maltez-da Costa M, Merkoçi A (2009) Rapid identification and quantification of tumor cells using an electrocatalytic method based on gold nanoparticles. Anal Chem 81:10268-10274. https://doi.org/10.1021/ac902087k

41. Xing Y, Chaudry Q, Shen C, Kong KY, Zhau HE, Chung LW, Wang MD (2007) Bioconjugated quantum dots for multiplexed and quantitative immunohistochemistry. Nat Protoc 2:1152-1165

42. Xing Y, Rao J (2008) Quantum dot bioconjugates for in vitro diagnostics \& in vivo imaging. Cancer Biomark 4:307-319

43. Lakowicz JR (1999) Principles of fluorescence spectroscopy. Plenum Press, New York

44. Chivers CE, Koner AL, Lowe ED, Howarth M (2011) How the biotin-streptavidin interaction was made even stronger: investigation via crystallography and a chimaeric tetramer. Biochem J 435:55-63

45. Otieno BA, Krause CE, Rusling JF (2016) Bioconjugation of antibodies and enzyme labels onto magnetic beads. In: Kumar CV (ed) Methods in enzymology. Academic Press, London, pp $135-150$

Publisher's Note Springer Nature remains neutral with regard to jurisdictional claims in published maps and institutional affiliations. 